\title{
Rescate, promoción y difusión de la música mexicana como estrategia educativa para el fortalecimiento del patrimonio cultural nacional
}

\begin{abstract}
Rescue, promotion and dissemination of Mexican music as an educational strategy to strengthen the national cultural heritage
\end{abstract}

Resgate, promoção e disseminação da música mexicana como estratégia educacional para fortalecer o patrimônio cultural nacional

\author{
Beania Salcedo Moncada \\ Universidad Autónoma de Nuevo León, México \\ beania_salcedo@hotmail.com \\ https://orcid.org/0000-0002-5653-9625 \\ José María López Prado \\ Universidad Autónoma de Nuevo León, México \\ jmlopezprado@hotmail.com \\ https://orcid.org/0000-0001-9175-8914
}

\section{Resumen}

El Festival Internacional de Música Mexicana es una estrategia educativa que fortalece diversas áreas de oportunidad en los estudiantes de la Facultad de Música de la Universidad Autónoma de Nuevo León a través de la creación de una plataforma musical y social que pretende mantener una permanente actualización acerca de los compositores e intérpretes mexicanos. En sus cuatro ediciones ha sido el único festival dedicado exclusivamente a la música mexicana de concierto, siendo su principal objetivo rescatar, promover y difundir la música de estructura académica mediante la impartición de conferencias, talleres, clases magistrales, recitales de ensambles, coros y conciertos con orquesta de cámara, orquesta juvenil, banda sinfónica, orquesta filarmónica y orquesta sinfónica. En tal sentido, los objetivos de este proyecto de investigación-acción fueron 1) potenciar los conocimientos de 


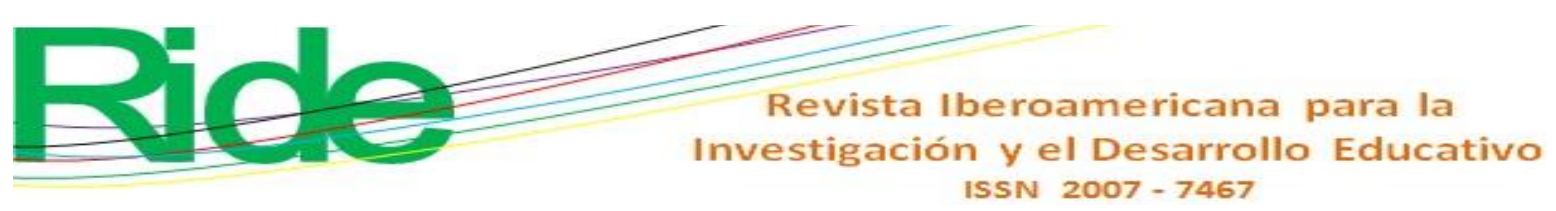

las estructuras formales de la música mexicana en los estudiantes del técnico medio en Música y de las licenciaturas con acentuación en composición, instrumentista, educación musical, canto y dirección coral que ofrece la Facultad de Música, 2) promover la creación de autores e intérpretes a través de exposiciones artísticas, 3) evaluar los cambios en el proceso de aprendizaje fomentando una enseñanza más ágil y activa, 4) utilizar el conocimiento de los elementos musicales y artísticos en el análisis de producciones artísticas propias y ajenas, y 5) compartir la experiencia musical de esta plataforma con el público en general como parte del patrimonio cultural del país. Para este estudio de investigación cualitativa se utilizó el diseño de la investigación-acción. Sobre esta base se efectuó un estudio descriptivo apoyado en la observación para analizar los diferentes procesos musicales en las obras de reciente creación, el acervo histórico de autores con trascendencia internacional y el desarrollo del pensamiento crítico en los estudiantes a través del análisis formal de la exposición artística presentada en el marco del IV Festival Internacional de Música Mexicana. Los resultados muestran que dicho evento se ha consolidado como una plataforma anual donde se impulsa la creación de propuestas artísticas nacionales que promueven información actualizada sobre los contenidos educativos y musicales que son parte de la formación profesional de facultades y conservatorios. Esta estrategia educativa, además, favorece el aprendizaje efectivo porque permite a los estudiantes conseguir una relación estrecha con los investigadores y especialistas foráneos a través de las conferencias, talleres y clases magistrales. Una de las temáticas principales fue el estudio de los instrumentos prehispánicos, lo cual se consiguió con un taller de elaboración de flautas y ocarinas con el fin de conocer los procesos usados desde hace siglos por artesanos mexicanos. Asimismo, se logró la participación de estudiantes, profesores e investigadores de la Facultad de Música a través de talleres, conferencias y exposición de piezas de autores mexicanos con obras de reciente creación en recitales y conciertos. El público que acudió a los conciertos y talleres manifestó su satisfacción por sentirse incluido en este proyecto, ya que tuvieron la oportunidad de participar en las actividades académicas y escuchar obras de música mexicana con profesionales en la materia y sin costo alguno.

Palabras clave: estrategia educativa, formación musical, música mexicana, participación social. 


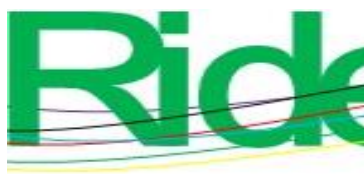

Revista Iberoamericana para la Investigación y el Desarrollo Educativo ISSN $2007-7467$

\section{Abstract}

The International Festival of Mexican Music is an educational strategy that strengthens various areas of opportunity in the students of the Faculty of Music of the Autonomous University of Nuevo León through the creation of a musical and social platform that aims to keep a permanent update on Mexican composers and performers. In its four editions it has been the only festival dedicated exclusively to Mexican concert music being its main objective to rescue, promote and disseminate the music of academic structure through the delivery of lectures, workshops, classes masterful, ensemble recitals, choirs and concerts with chamber orchestra, youth orchestra, symphony band, philharmonic orchestra and symphony orchestra. The objectives of this research-action project are: 1) to enhance knowledge of the formal structures of Mexican music in the students of the Middle Technician in Music and of the bachelor's degrees with accentuation in composition, instrumentalist, education musical, singing and choral direction offered by the Faculty of Music, 2) promoting the creation of authors and performers through artistic exhibitions, 3) evaluating changes in the learning process by encouraging more agile and active teaching, 4) using the knowledge of the musical and artistic elements in the analysis of own and external artistic productions, and 5) share the musical experience of this platform with the general public as part of the cultural heritage of the country. For this qualitative research study, the design of research-action was used, based on this design, a descriptive study was carried out on the basis of observation, with the aim of studying the different musical processes in the works of recent creation, the historical collection of authors of international significance and the development of critical thinking in students through the formal analysis of the artistic exhibition presented in the framework of the IV International Festival of Mexican Music. The results showed that the International Mexican Music Festival has established itself as an annual platform where the creation of national artistic proposals is promoted by maintaining up-to-date information on educational content and which are part of the professional training of faculties and conservatories, there were 28 national proposals to participate in this forum. It is an educational strategy that promotes effective learning by allowing students to achieve a close relationship with foreign researchers and specialists through lectures, workshops and master classes. One of the main themes was the study of pre-Hispanic instruments strengthened with a workshop of making flutes and ocarinas in order to know the processes that have been used for centuries by Mexican artisans. Students, professors and researchers 


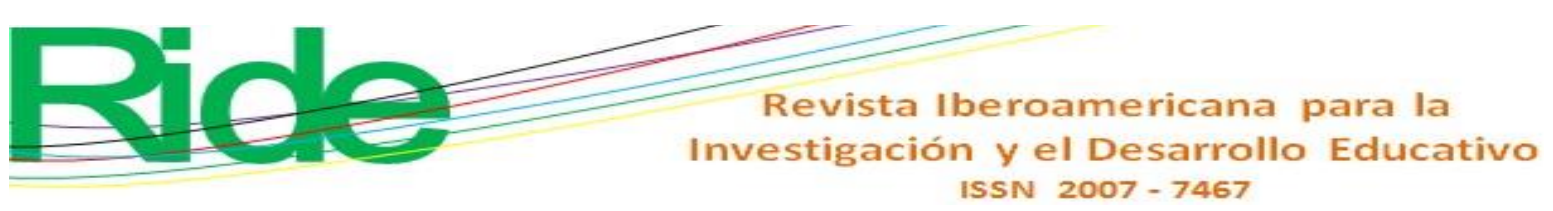

from the Faculty of Music were involved through workshops, conferences and exhibition of works by Mexican authors with newly created works in recitals and concerts. The audience who attended the concerts and workshops expressed their satisfaction that they felt included in this research project because they have the opportunity to participate in academic activities and listen to Works of Mexican music with professionals in the field and at no cost.

Keywords: educativa strategy, musical training, Mexican music, social participation.

\section{Resumo}

O Festival Internacional de Música Mexicana é uma estratégia educacional que fortalece diversas áreas de oportunidade entre os alunos da Faculdade de Música da Universidade Autônoma de Nuevo León, através da criação de uma plataforma musical e social que visa manter uma atualização permanente sobre Compositores e intérpretes mexicanos. Em suas quatro edições, foi o único festival dedicado exclusivamente à música de concerto mexicana, cujo objetivo principal é resgatar, promover e divulgar a música da estrutura acadêmica por meio de palestras, oficinas, master classes, recitais de assembléias, coros e shows. com orquestra de câmara, orquestra juvenil, banda sinfônica, orquestra filarmônica e orquestra sinfônica. Nesse sentido, os objetivos deste projeto de pesquisa-ação foram: 1) aprimorar o conhecimento das estruturas formais da música mexicana nos alunos do técnico médio em música e os graus com ênfase em composição, instrumentista, educação musical, canto; e direção coral oferecida pela Faculdade de Música, 2) promover a criação de autores e intérpretes por meio de exposições artísticas, 3) avaliar as mudanças no processo de aprendizagem, incentivando um ensino mais ágil e ativo; 4) usar o conhecimento de elementos musicais e artísticos na análise de produções artísticas próprias e de outras pessoas e 5) compartilham a experiência musical dessa plataforma com o público em geral como parte do patrimônio cultural do país. Para este estudo de pesquisa qualitativa, foi utilizado o desenho da pesquisa-ação. Com base nisso, foi realizado um estudo descritivo, baseado em observação, para analisar os diferentes processos musicais das obras recém-criadas, o acervo histórico de autores de importância internacional e o desenvolvimento do pensamento crítico nos alunos através da análise formal da exposição. Artística apresentada no âmbito do IV Festival Internacional de Música Mexicana. Os resultados mostram que este evento foi consolidado como uma plataforma anual onde é promovida a criação de propostas artísticas 


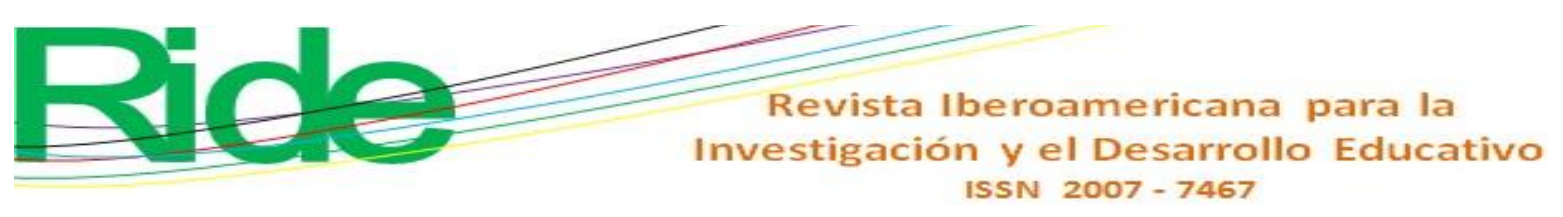

nacionais que promovam informações atualizadas sobre os conteúdos educacionais e musicais que fazem parte da formação profissional de faculdades e conservatórios. Essa estratégia educacional também favorece o aprendizado efetivo, pois permite que os alunos mantenham um relacionamento próximo com pesquisadores e especialistas estrangeiros por meio de conferências, workshops e master classes. Um dos temas principais foi o estudo de instrumentos pré-hispânicos, realizado com um workshop para a elaboração de flautas e ocarinas, a fim de conhecer os processos utilizados durante séculos pelos artesãos mexicanos. Da mesma forma, a participação de estudantes, professores e pesquisadores da Faculdade de Música foi alcançada através de oficinas, conferências e exibição de peças de autores mexicanos, com trabalhos recentemente criados em recitais e concertos. O público que assistiu aos concertos e oficinas expressou sua satisfação por se sentir incluído neste projeto, pois teve a oportunidade de participar de atividades acadêmicas e ouvir música mexicana com profissionais da área, sem nenhum custo.

Palavras-chave: estratégia educacional, treinamento musical, música mexicana, participação social.

Fecha Recepción: Septiembre 2019

Fecha Aceptación: Diciembre 2019

\section{Introducción}

La música mexicana es una de las manifestaciones artísticas más significativas del acervo cultural de nuestro país porque contribuye a forjar los lazos de identidad entre las personas. "Entre las fuentes escritas destacan los diferentes códices que fueron hechos a partir de una escritura pictográfica con contenido mnemotécnico, realizados en diferentes periodos históricos en los que se ilustra la forma de tocar ciertos instrumentos y la actividad social a la que estaba ligada la música" (Híjar, 2009,p.183). Desde la época prehispánica, de hecho, este tipo de expresión constituía una actividad primordial en todos los aspectos de la vida diaria, particularmente en los ritos, las ceremonias o los combates que se practicaban: 


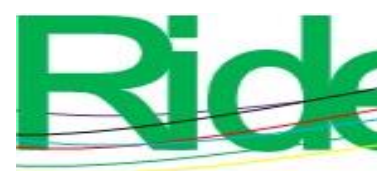

Revista Iberoamericana para la
Investigación y el Desarrollo Educativo
ISSN $2007-7467$

En los templos existía personal dedicado a diversas funciones como el ometochtzin maestro de todos los cantores que tenían a cargo cantar en los cués (templos); el Tlapizcatzin que enseñaba, regía y corregía a los cantantes y llevaba el compás del teponaztli; canto residente de los cués; el Mixtecoatzalotla que instruye a los jóvenes en la ceremonia del fuego; limpieza del templo y a tañer los instrumentos del mixcoacalli (Marroquín y Cavazos, 2012, p. 28).

Ahora bien, aunque en la actualidad no existen registros que indiquen con exactitud cómo era la música en la época precolombina, mediante los hallazgos arqueológicos que aún se conservan (imágenes en esculturas, dibujos en códices, relatos míticos citados por algunos frailes, etc.) se pueden apreciar las distintas prácticas musicales de nuestros ancestros, las cuales han sobrevivido en diversas regiones del país y han sido usadas para ciertas festividades.

Entre los manuscritos referidos al empleo de los instrumentos y el significado de la música en esa época se pueden mencionar dos: "uno llamado Cantares mexicanos, que se halla en la Biblioteca Nacional de México; el otro, conocido con el curioso título de Romances de los señores de la Nueva España, se guarda en la Colección Latinoamericana Nettie Lee Benson de la Universidad de Texas en Austin” (León, 2019, p. 35).

La música siempre ha sido parte de un contexto social y cultural determinado, de ahí que no sea un tipo de expresión humana que se produzca aisladamente. En otras palabras, siempre existe una sociedad que la influencia, y dentro de ella hay creadores, transmisores y receptores que hacen que este valor cultural se vuelva parte de la identidad del momento. En el caso de nuestros ancestros, las actividades artísticas eran diferentes a las del mundo occidental actual, ya que sus valores eran muy profundos:

El que hoy nombramos 'artista' era un ser predestinado al cual se educaba en centros especiales, en donde se adentraba en los mitos y tradiciones de su pueblo. El artista se trasformaba mediante su educación en el ser que sabía 'dialogar con su propio corazón' y se convertía en un tlayoltehuaiani, 'aquel que introduce el simbolismo de la divinidad en cosas"” (Ramírez de la Fuente, 2013, p. 15). 


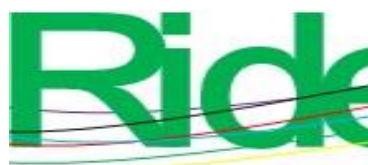

Revista Iberoamericana para la Investigación y el Desarrollo Educativo ISSN $2007-7467$

Por todo lo anterior, se puede afirmar que la herencia musical de México (un país de tan amplia pluriculturalidad) debe ser conservada como parte de la educación integral de las generaciones actuales y futuras.

\section{Estrategia educativa y social para el enriquecimiento de la formación musical del país}

El Festival Internacional de Música Mexicana es considerado como una estrategia dentro de la Facultad de Música de la Universidad Autónoma de Nuevo León (UANL) debido a que sus actividades desarrolladas (talleres, conferencias, clases magistrales, etc.) están enfocadas en el desarrollo académico de la población y el fortalecimiento de diversas asignaturas (p. ej., Historia de la Música en México). La estrategia educativa es definida por Gargallo, Almerich, Suárez-Rodríguez y García-Félix (2012) de la siguiente manera:

Es el conjunto de acciones y procedimientos, mediante el empleo de métodos, técnicas, medios y recursos que el docente emplea para planificar, aplicar y evaluar de forma intencional, con el propósito de lograr eficazmente el proceso educativo en una situación de enseñanza-aprendizaje específica, según sea el modelo pedagógico y/o andragógico, por contenidos, objetivos y/o competencias para las cuales las elabora y desarrolla (p. 22).

La planificación del Festival Internacional de Música Mexicana se realiza durante doce meses y es avalada por un comité conformado por investigadores, profesores y estudiantes de servicio social. En ese proceso se analizan los tipos de estrategias diseñadas para cada temática, con lo cual se procura que los estudiantes consigan un aprendizaje significativo. Al respecto, Gargallo et al. (2012) acotan que "la estrategia educativa es un conjunto organizado, consciente e intencional de lo que hace el aprendiz para lograr con eficacia un objetivo de aprendizaje en un contexto social dado, integrando elementos afectivomotivacionales y de apoyo, metacognitivos y cognitivos” (p. 22). Las estrategias empleadas para este magno encuentro han sido las siguientes:

- Conferencias magistrales.

- Clases magistrales.

- Escucha de obras musicales de rescate e innovación.

- Exposición artística de los estudiantes de la Facultad de Música. 


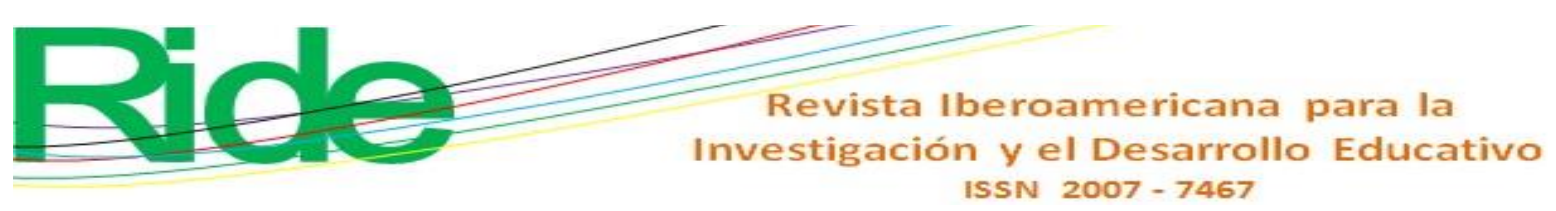

- Taller de elaboración de instrumentos prehispánicos.

- Exposición de instrumentos prehispánicos.

- Taller de metodología solfeo a la mexicana.

- Instrumento de medición en cada uno de los eventos para analizar los resultados.

\section{Festival Internacional de Música Mexicana}

El origen de este proyecto de investigación comienza en 2016 a través de la aprobación de la convocatoria nuevo PTC de PRODEP, otorgado a la doctora Beania Salcedo Moncada, perteneciente a la planta docente de la Facultad de Música de la UANL. Desde entonces, se han sumado a esta actividad las siguientes instituciones: Coordinación de Música

y Ópera de Bellas Artes, CONARTE, FONCA, Orquesta Sinfónica de UANL, Extensión y Cultura de la UANL, Orquesta Filarmónica del Desierto de Coahuila, Orquesta Esperanza Azteca, Red de Orquesta para la Igualdad y Centro de Investigación, Innovación y Desarrollo de las Artes.

Este es el único festival de estructura académica a nivel nacional enfocado en la música mexicana. Su objetivo primordial es rescatar la música de autores consagrados y desconocidos, así como enriquecer la producción de obras actuales y promover la exposición artística de compositores e intérpretes con la finalidad de mantener una formación actualizada e impulsar la creación de nuevos grupos instrumentales y corales a nivel nacional e internacional.

\section{Festival Internacional de Música Mexicana}

El festival del año 2019 se efectuó entre el 19 y el 25 de septiembre. En total, se efectuaron 28 eventos, dentro de los cuales hubo tres conferencias magistrales, dos conciertoconferencias, dos talleres, cuatro clases magistrales, doce recitales y cuatro conciertos con orquesta completa. Asimismo, participaron de forma activa estudiantes y maestros de la Facultad de Música. Las sedes elegidas fueron las siguientes: Facultad de Música, Centro de Investigación e Innovación de las Artes, aula magna del Colegio Civil, teatro universitario, preparatoria n. ${ }^{\circ} 2$ de la UANL, Facultad de Artes Visuales y auditorio San Pedro. 


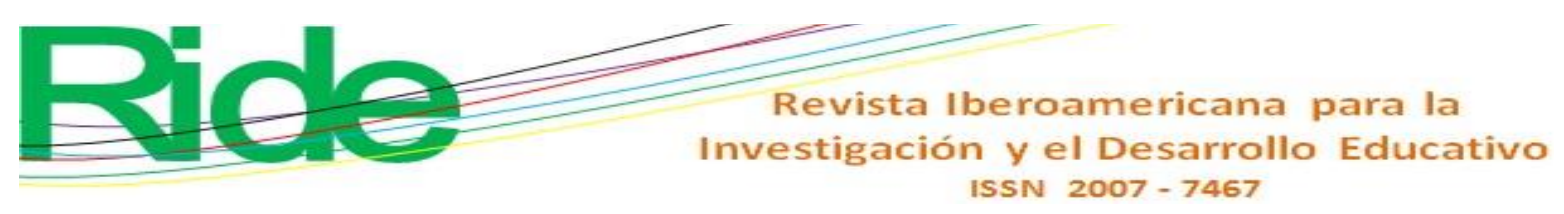

\section{Objetivos}

- Realizar el Festival Internacional de Música Mexicana como una estrategia para promover el aprendizaje efectivo.

- Potenciar los conocimientos de las estructuras formales de la música mexicana en los estudiantes del técnico medio en Música y de las licenciaturas con acentuación en composición, instrumentista, educación musical, canto y dirección coral ofertadas en la Facultad de Música.

- Promover la creación de autores e intérpretes a través de exposiciones artísticas.

- Evaluar los cambios en el proceso de aprendizaje fomentando una enseñanza más ágil y activa.

- Utilizar el conocimiento de los elementos musicales y artísticos en el análisis de producciones artísticas propias y ajenas.

- Compartir la experiencia musical de esta plataforma con el público en general como parte del patrimonio cultural del país.

\section{Metodología}

Para este estudio de investigación cualitativa se utilizó el diseño de investigaciónacción, el cual es definido por Lewin (1946, citado por Latorre, 2013) como "una metodología que persigue a la vez resultados de acción e investigación; como un diálogo entre la acción y la investigación. Conlleva la comprobación de ideas en la práctica como medio de mejorar las condiciones sociales e incrementar el conocimiento" (p. 27).

Sobre la base de este diseño, se efectuó un estudio descriptivo con un enfoque práctico donde "los resultados y percepciones ganados desde la investigación no solo tienen importancia teórica para el avance del conocimiento en el campo social, sino que ante todo conducen a mejoras prácticas durante y después del proceso de investigación” (Latorre, 2013, p. 25).

Los participantes fueron estudiantes de la Facultad de Música, específicamente del nivel técnico medio y de las licenciaturas en Música con acentuación en composición, instrumentista, educación musical, canto y dirección coral. Asimismo, colaboraron 19 profesores de la Facultad de Música, 16 profesores foráneos y 3 investigadores. 


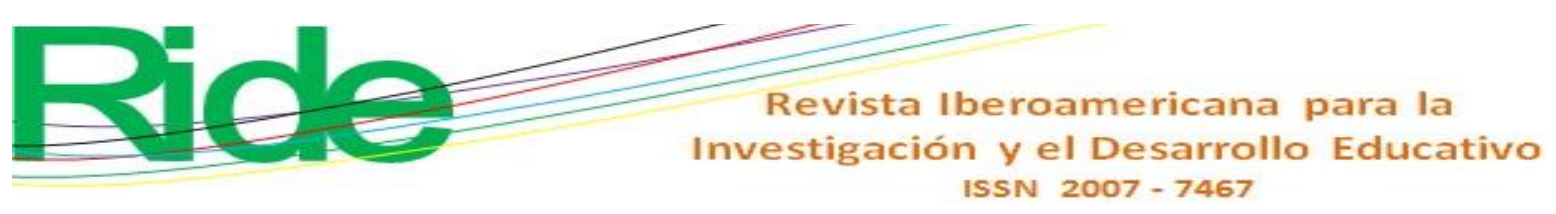

La recogida de datos se efectuó mediante la observación de los eventos académicos (clases magistrales, conferencias, recitales, talleres y conciertos de orquestas), los cuales fueron registrados a través de grabaciones en video y fotografías. El instrumento de medición consistió en un cuestionario de preguntas cerradas con una escala de estimación descriptiva. "Las preguntas de estimación tienen como finalidad clasificar las respuestas en grado, intensidad, introducen el elemento de medida, generalmente evalúan opiniones o actitudes" (García-Córdoba, 2012, p. 76). La muestra para el cuestionario fue de 380 participantes.

\section{Infraestructura y apoyo técnico disponible}

Las instalaciones de la Facultad de Música usadas fueron las que se nombran a continuación:

1. Auditorio Silvestre Revueltas: Este cuenta con el siguiente equipamiento:

- Cámara fotográfica.

- Cámara de video.

- Proyector.

- Pantalla.

- Piano.

- Butacas.

- Escenario.

2. Aula de Corales y Aula de Orquestales: Cuentan con el siguiente equipamiento:

- Piano.

- Atriles.

- Sillas.

- Proyector.

- Pantalla.

- Área para coros.

3. Sala de Multimedia: Cuenta con el siguiente equipamiento:

- Sala de grabación.

- Computadora.

- Mezcladora.

- Micrófonos.

- Cámara de video. 
4. Aula 2 para taller de elaboración de instrumentos prehispánicos: Cuenta con el siguiente equipamiento:

- Sillas.

- Mesas.

- Pizarrón.

- Computadora.

- Proyector.

5. Auditorio San Pedro: Cuenta con el siguiente equipamiento:

- Escenario.

- Butacas.

- Equipo de grabación.

- Concha acústica.

- Vestíbulo.

6. Aula magna de Colegio Civil: Cuenta con el siguiente equipamiento:

- Escenario.

- Butacas.

- Equipo de grabación.

- Concha acústica.

- Vestíbulo.

- Proyector.

- Pantalla.

- Micrófonos.

7. Auditorio de la Facultad de Artes Visuales: Cuenta con el siguiente equipamiento:

- Escenario.

- Butacas.

- Equipo de grabación.

- Vestíbulo.

8. Preparatoria $n .^{\circ} 2$ de la Universidad Autónoma de Nuevo León: Cuenta con el siguiente equipamiento:

- Auditorio al aire libre.

- Sillas.

- Atriles.

- Equipo de grabación. 


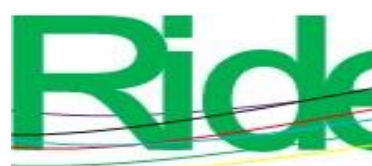

Revista Iberoamericana para la Investigación y el Desarrollo Educativo ISSN $2007-7467$

9. Centro de Investigación e Innovación y Desarrollo de las Artes: Cuenta con el siguiente equipamiento:

- Sala para conferencias.

- Sala para talleres.

- Piano.

- Pantalla.

- Proyector.

\section{Resultados}

El IV Festival Internacional de Música Mexicana inició sus actividades el jueves 19 de septiembre de 2019 a las 10:00 horas en el Centro de Investigación, Innovación y Desarrollo de las Artes con la conferencia Los códices y los instrumentos prehispánicos, con la participación de la M. A. Mirna Marroquín. En esta intervención se abordó la temática de la iconografía musical que hace referencia a los instrumentos que aparecen en algunos de los códices premestizos e inmediatos a la conquista. Al respecto, vale acotar que "actualmente existen en todo el mundo cerca de 500 códices del México antiguo; de estos, solo 16 son prehispánicos y el resto posmestizos” (González-Quintanilla, 1991, p. 74). A estos se les llama códices por los nombres de los coleccionistas que los poseen o por los lugares a los que fueron llevados en algunos países del extranjero. El contenido de estos puede abarcar entre temas de carácter religioso, mitológico o calendárico, aunque también se pueden hallar documentos que describen el tipo de instrumentos musicales usados según la festividad.

Los códices o libros pintados contienen imágenes musicales. En el caso de los naandeye o libros mixtecos, sus escrituras pintadas muestran representaciones de instrumentos musicales, el signo del canto y personajes danzando. De acuerdo con el contexto en el que se encuentre, cada una puede mostrar diferentes funciones, como las de determinar el nombre de topónimos, antropónimos, sobrenombres, ejecución musical o su función como objetos rituales. Estos elementos también están presentes en el Códice Borgia y el Códice Borbónico (Gómez, 2006, p. 3).

Luego de la anterior conferencia, a las 12:00 horas en el aula de Corales, se presentó la clase magistral de violín con el maestro Manuel Lozano Torres, uno de los pocos músicos mexicanos graduados en una de las escuelas de mayor prestigio en el mundo: la Juilliard School de Nueva York. Lozano Torres ha impartido cursos de perfeccionamiento de violín y 


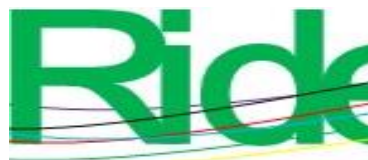

Revista Iberoamericana para la
Investigación y el Desarrollo Educativo
ISSN $2007-7467$

música de cámara en la Escuela Superior de Música de Monterrey, así como en la Florida State University en Gainesville y en la Universidad de Colorado (ambas de Estados Unidos), y también en la Universidad de Hokkaido y en la Hokkaido International School (las dos ubicadas en Japón). Esta clase magistral tuvo un gran impacto entre la comunidad estudiantil (participaron activamente 6 alumnos y 32 más fueron oyentes).

A las 16:00 horas en el Centro de Investigación e Innovación y Desarrollo de las Artes tuvo lugar el concierto-conferencia de piano y violonchelo del Dúo Casals, con la intervención de la doctora Beania Salcedo Moncada y el doctor José María López Prado. La temática fue el nacionalismo y la música mexicana. El enfoque estuvo en obras de Luis Sandi, Arturo Márquez, Arturo Rodríguez, Emanuel Arias y Luna, Arturo Rodríguez y Manuel M. Ponce (este último considerado el padre del nacionalismo musical en México).

En 1912, Ponce vivía una de sus épocas de mayor creatividad y emprende su labor nacionalista armonizando cantos y melodías populares para piano y para piano y canto sin dejar de componer obras de su propia inspiración que manifiestan influencias de autores del romanticismo como Franz Schubert o Robert Schumann, pero el compositor mexicano ya era dueño de sus propios recursos creativos y a pesar de su admiración por los maestros alemanes logra que sus propios Lieder mantengan su sabor de canción romántica mexicana, congruente con su idea del nacionalismo musical (Díaz y Díaz, 2003, p. 147).

Manuel M. Ponce —además de tener una producción muy generosa de obras musicales - fue un gran investigador y promotor de la música mexicana; colaboró en crónicas y artículos de gran valor, así como en periódicos y publicaciones académicas. "Fundó y dirigió tres revistas musicológicas ineludibles: Revista Musical de México (Ciudad de México, 1919-19209), Gaceta Musical (París, 1928-1929) y Cultura Musical (Ciudad de México, 1936-1937). Concluyó los volúmenes Escritos y composiciones musicales (1917) y Nuevos escritos musicales publicado póstumamente el 3 de noviembre de 1948" (Sánchez, Lioba, Carvajal y Castillo, 2016, p. 268).

Posterior a este concierto-conferencia, a las 18:00 horas en el Centro de Investigación e Innovación y Desarrollo de las Artes, se presentó el recital de canto Alma mía, con la participación de los maestros Karina Ríos, Edgar Garza y Jorge Martínez, quienes ejecutaron canciones mexicanas de los compositores Manuel M. Ponce, María Grever, Jorge del Moral, Tata Nacho, Felipe Villanueva, Alfonso Esparza Oteo y Agustín Lara. Esta exposición vocal 


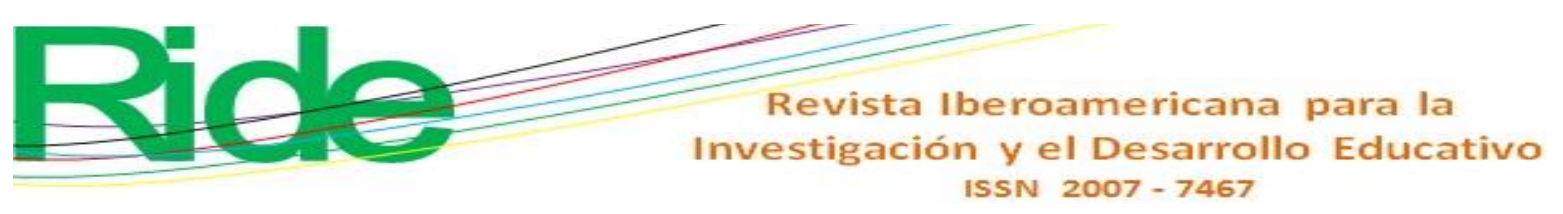

estuvo claramente enfocada en canciones mexicanas de los periodos nacionalista, colonial y romántico, que han trascendido por su temática popular, pero que fueron rescatadas con estructuras académicas para ser interpretadas por una soprano, un tenor y un pianista profesional.

Finalmente, la inauguración oficial del IV Festival Internacional de Música Mexicana se realizó a las 20:00 horas en el teatro universitario con la presentación de la orquesta sinfónica de la Universidad Autónoma de Nuevo León, ensamble representativo del Estado y uno de los conjuntos musicales más relevantes de México. Actualmente se encuentra bajo la dirección artística de Eduardo Díaz Muñoz, y en esta ocasión participó Cuauhtémoc Rivera como invitado solista. La orquesta abrió con la obra El salón México, pieza sinfónica en un movimiento compuesta entre 1932-1936 por Aaron Copland, la cual usa música autóctona mexicana de manera extensiva. Esta obra es considerada como un poema tonal: es la descripción de un salón de baile típico en la capital de México. La orquesta sinfónica de México presentó esta obra por primera vez bajo la dirección de Carlos Chávez en 1937 y posteriormente se estrenó en Estados Unidos en 1938.

También se escuchó la serenata para violín, arpa, cuerdas y percusión de Leonard Bernstein, así como la obra Tu son, tu risa, tu sonrisa de Daniel Catán y finalizó el concierto con el emblemático Danzón $n .^{\circ} 2$ de Arturo Márquez seguido del huapango de José Pablo Moncayo.

Al día siguiente, las actividades comenzaron a las 10:00 horas en el Centro de Investigación Innovación y Desarrollo de las Artes con la conferencia El pensamiento crítico como parte del desarrollo musical de México, presentada por el M. E. Cesar Botello. Este trabajo de investigación se centró en las decisiones que el estudiante debe de tomar a lo largo de su carrera utilizando el pensamiento crítico como base para desarrollar la creatividad y para lograr un óptimo avance en sus metas profesionales. Esta es una estrategia aplicada en la clase de piano a nivel técnico y licenciatura.

A las 15:00 horas en el Aula de Corales de la Facultad de Música se impartió la clase magistral del maestro Gerardo Tamez, compositor y guitarrista con una trayectoria artística de 52 años, y referente nacional e internacional en materia de composición, arreglo, interpretación y docencia de la música mexicana y latinoamericana con gran incidencia en la vida cultural del país. A esta actividad acudieron 4 ensambles de guitarra y más de 45 estudiantes que pudieron abordar las obras del maestro Tamez bajo su supervisión. Gracias 


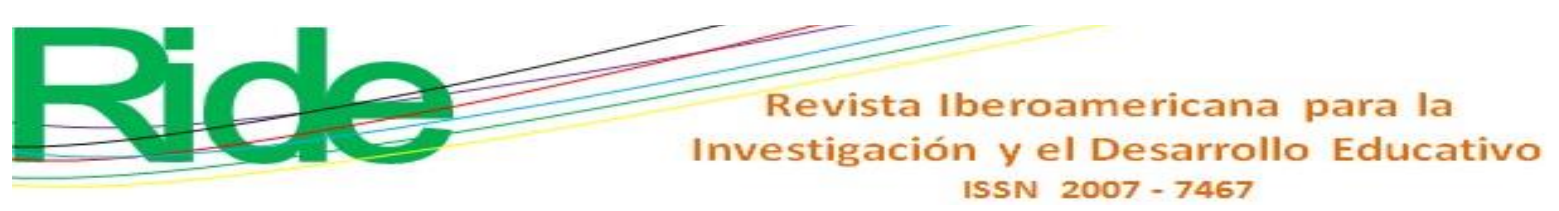

a esto los alumnos tuvieron la posibilidad de enriquecer sus conocimientos compartiendo directamente con el afamado compositor.

Posteriormente, a las 17:00 horas en el Aula de Orquestales se presentó el conciertoconferencia La música mexicana del siglo XX, con la participación de la doctora Flora Barrientos Pivot, quien expuso la obra del compositor mexicano Mario Ruiz Armengol, pianista y compositor nacido en Veracruz en 1914, hijo del notable pianista y director de orquesta don Ismael Ruiz Suárez y de doña Rosa Armengol.

En esta participación se expusieron los inicios musicales de Mario Ruiz Armengol, quien a los 16 ya era miembro fundador de la XEW, donde empieza a adquirir fama como compositor, arreglista y director de orquesta. Luego, en 1936 estudia armonía y contrapunto con el maestro José Rolón. A partir de 1942, año en que conoce e inicia su amistad con Manuel M. Ponce, trabaja en la cinematografía mexicana, donde compone música para diferentes películas. Su gran obra pianística incluye 31 piezas infantiles, 19 danzas cubanas, 16 estudios, 16 reflexiones, 32 miniaturas, 5 valses, scherzos, minuetos, sonatas, fantasías, preludios y música para piano a cuatro manos, música de cámara para piano y violín, violonchelo, arpa y flauta. Muchos de los estudiantes de piano tocan cada semestre piezas de este gran compositor, por lo que esta conferencia resultó ser una estrategia de fortalecimiento para el abordaje de las obras.

Finalmente, a las 20:00 horas en el auditorio San Pedro se presentó la Orquesta Filarmónica del Desierto de Coahuila bajo la dirección artística de Natanael Espinoza y el violonchelista Álvaro Bitran. En esta actividad se ofreció el concierto n. ${ }^{\circ} 1$ para violonchelo y orquesta del compositor Eugenio Toussaint, quien desarrolló una fecunda carrera como compositor de música de concierto. A la par de su interés por el jazz, formó parte del Sistema de Creadores del Fondo para la Cultura y las Artes. En 1982 escribió el concierto para violonchelo y orquesta, estrenado en 1991 por la orquesta sinfónica de la Sociedad Filarmónica de Conciertos, con Álvaro Bitran como solista, violonchelista mexicano que ha sido condecorado por el Gobierno mexicano con la medalla de Bellas Artes en el año 2000 y por el Gobierno chileno con la Orden al Mérito Pablo Neruda en 2014.

La Orquesta Filarmónica del Desierto de Coahuila de Zaragoza se creó el 10 de junio de 2014 con la firma del decreto por el gobernador del estado, Rubén Moreira Valdez, con la finalidad de promover la cultura y la música de manera permanente. Está dirigida por el 


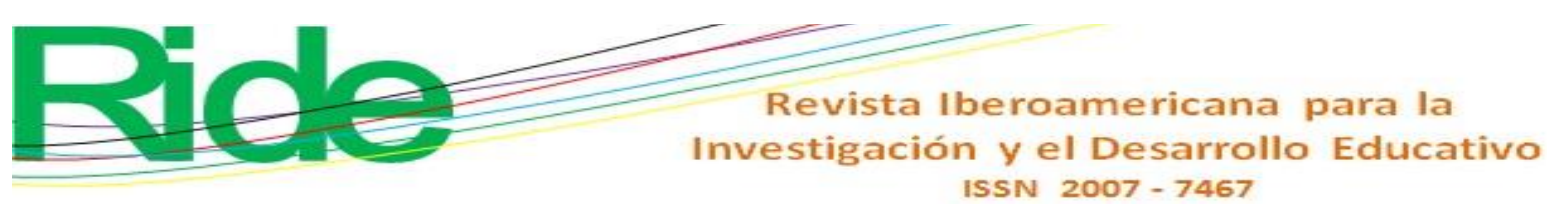

maestro Natanael Espinoza, originario de la ciudad de Ensenada Baja California y fundador de esta maravillosa agrupación.

Por otra parte, a las 11:00 horas del sábado 21 de septiembre iniciamos en la sala de multimedia de la Facultad de Música la clase magistral de violonchelo del Maestro Álvaro Bitran. Asistieron 32 alumnos del técnico medio y de la licenciatura en instrumentista con acentuación en violonchelo. Los estudiantes expusieron las obras estudiadas durante el semestre y pudieron fortalecer los conocimientos del instrumento; además, pudieron acercarse a uno de los especialistas de mayor trayectoria en el país.

A las 12:00 horas en el auditorio de la Facultad de Artes Visuales se presentó la banda sinfónica de la Facultad de Música, bajo la dirección del maestro invitado Jesús Sánchez. Esta agrupación es un ensamble universitario nacido en enero de 2016 enfocado en la introducción y desarrollo de los alumnos de música hacia el género de banda sinfónica. Sus filas están conformadas por los alumnos de todas las carreras de la Facultad de Música, licenciatura, técnico medio, técnico superior universitario y capacitación musical. Su fundadora y directora es Alma Patricia Huerta. En la actividad se presentó un programa completo de autores mexicanos con arreglos para esta agrupación, que cuenta con 56 integrantes. Asimismo, se interpretaron piezas de autores como Estanislao García Espinoza, Velino M. Preza, Macedonio Alcalá, Juventino Rosas, Arturo Márquez y José Pablo Moncayo.

A las 17:00 horas en el aula de Orquestales se ofreció un recital de la academia de piano, donde participaron 10 estudiantes de piano dirigidos por las maestras Natalia Tibets, Sveltlana Pyrkova, Antonina Dragan y Delia de la Torre. El repertorio estuvo constituido por autores mexicanos como Manuel M. Ponce, Luis G. Jordá, José Pablo Moncayo, Mario Ruiz Armengol y Federico Ibarra. Fue un recital muy emotivo, para lo cual se seleccionaron a los mejores estudiantes de la academia de piano.

El lunes 23 de septiembre a las 10:00 horas en el Centro de Investigación Innovación y Desarrollo de las Artes, se efectuó el taller Solfeo a la Mexicana con la doctora Elda Nelly Treviño, y con una asistencia de más de 70 estudiantes de técnico medio y licenciatura. El taller se enfocó en el solfeo aplicado a melodías mexicanas, aspecto esencial para que a los alumnos se les facilite leer y escuchar ciertos modelos rítmicos y melódicos. 


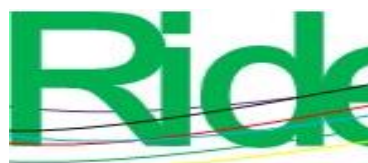

Revista Iberoamericana para la
Investigación y el Desarrollo Educativo
ISSN $2007-7467$

Después, a las 16:00 horas en el aula magna de Colegio Civil, se presentó el ensamble de percusiones de la Facultad de Música, bajo la dirección del maestro Noel Savón Ferrier, coordinador del área de percusiones. El objetivo fue fortalecer el aprendizaje de los estudiantes a través de la formación de pequeños grupos, abarcando principalmente un repertorio de autores mexicanos y ritmos latinos. Este concierto también fue didáctico porque en cada una de las obras se desarrolló una charla introductoria para acercar al público a los contextos históricos y culturales de los compositores expuestos. En el escenario participaron doce estudiantes de la Facultad de Música.

A las 18:00 horas en el aula magna de Colegio Civil se llevó a cabo el recital de piano del maestro Héctor Rojas, uno de los mejores pianistas mexicanos y el único que tiene la integral de Manuel M. Ponce. Estudió en la Escuela Nacional de Música de la UNAM y en el Conservatorio Nacional de Música con el distinguido pianista Carlos Vázquez, heredero universal de Manuel M. Ponce. Sus estudios los culminó con una beca otorgada en el concurso Pianista Sala Chopin, lo cual le permitió estudiar en la Academia de Música de Viena, Austria. El repertorio que se ofreció en este recital inició con obras representativas, especialmente del periodo nacionalista de Manuel M. Ponce, quien es considerado como el padre del nacionalismo musical en México. Al respecto, Chávez (2018) expresa:

La centralidad de la Revolución inspiró la invención de un nacionalismo mexicano a través del arte y las bellas artes en particular. La expresión del sentimiento nacional se encausó mediante la apropiación y adaptación del modernismo europeo de forma tal que pudiese representar el pasado mexicano y su destino (p. 436).

La culminación de este recital estuvo a cargo del emblemático Vals capricho de Ricardo Castro.

Al respecto, Sánchez, Carvajal, Lioba, y Castillo (2016) mencionan que "la pianística mexicana se constituye de factores determinantes basados en la ejecución individual del intérprete y en la objetivación de las respuestas interpretativas, las cuales extienden propiedades musicales de cada composición pianística (p. 177)

Finalmente, a las 20:00 horas en el aula magna de Colegio Civil se presentó la orquesta de cámara de la Universidad Autónoma de Nuevo León, bajo la dirección del maestro Claudio Tarris y los guitarristas Alfredo Amezcua y Gerardo Tamez. Se presentó el concierto del sur de Manuel M. Ponce, estrenado en Montevideo por Andrés Segovia el 14 


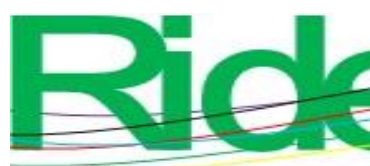

Revista Iberoamericana para la
Investigación y el Desarrollo Educativo
ISSN $2007-7467$

de octubre de 1941. El concierto del sur tiende a centrar sus referencias en la música española, a través de giros y sugerencias muy afines con el sonido árabe-andaluz, "la portentosa obra del compositor que abarca todos los géneros y tiene ramificación especial la dedicación a la guitarra, como consecuencia de su larga e íntima amistad con Andrés Segovia”(Barrón,J., 2014,p.223). Posteriormente, se presentó el concierto San Ángel, interpretado por su autor, el maestro Tamez, cuyas influencias, en gran medida, se hallan en el folclore nacional y latinoamericano. La obra de este autor ha sido publicada por las editoriales francesas Max Eschig y Salabert, y la estadounidense Mel Bay.

El martes 23 de septiembre a las 10:00 horas las actividades iniciaron en el aula 2 de la Facultad de Música, con el taller de elaboración de instrumentos prehispánicos. Los estudiantes participaron de forma masiva y pudieron elaborar flautas y ocarinas con instrucción de los integrantes del grupo de Venado Azul provenientes del estado de Hidalgo. Se brindaron múltiples explicaciones acerca de los aerófonos creados en barro y las técnicas utilizadas y preservadas desde hace siglos.

A las 12:00 horas en el aula de Orquestales se realizó la clase magistral de piano con el maestro Héctor Rojas. Participaron 18 estudiantes y el repertorio principal fue del compositor Manuel M. Ponce.

A las 16:00 horas en el auditorio Silvestre Revueltas se ofreció el recital de coros de la Facultad de Música bajo la dirección de la doctora Patricia Cavazos. En este encuentro se fusionaron los grupos del nivel técnico medio con los de licenciatura, con lo cual se consiguió un programa muy completo, con arreglos de canciones tradicionales mexicanas como $A y$, sandunga y La bruja, y obras de Chucho Monge, Alfonso Esparza Oteo, Agustín Lara, Agustín Ramírez, Guadalupe Trigo, Álvaro Carrillo y Pedro de Urdimalas.

A las 18:00 horas en el auditorio Silvestre Revueltas se presentó el recital de saxofón y percusiones Sinéresis. Los participantes fueron Andrés Torres (egresado de la Facultad de Música) y Eusebio Sánchez (egresado de la Escuela Superior de Música y Danza), ambos ejecutantes con una amplia trayectoria artística y con el firme propósito de difundir la música contemporánea de compositores mexicanos. Las obras que se presentaron fueron de los compositores Eduardo Caballero, Salvador Torré, Daniel Román y Mario Lavista.

A las 18:00 horas en la preparatoria ${ }^{\circ}{ }^{\circ} 2$ de la UANL se realizó simultáneamente el concierto con la red de orquestas juveniles La Llave de la Igualdad, formada actualmente por 28 orquestas ubicadas en los municipios del área metropolitana del estado de Nuevo León, 


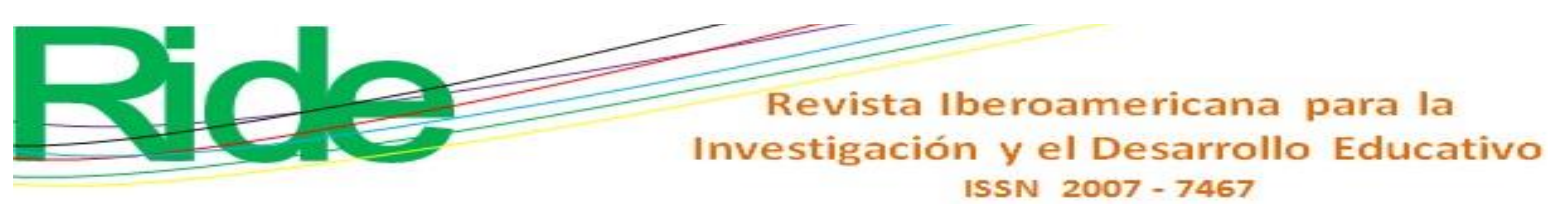

con más de mil jóvenes habitantes de colonias vulnerables. Estas orquestas nacieron como parte de una estrategia de prevención por parte del Gobierno del estado de Nuevo León en 2013. La participación de esta agrupación fue muy enriquecedora para los estudiantes de la preparatoria porque pudieron disfrutar de la música mexicana de concierto. Las opiniones fueron positivas en todos los aspectos.

El miércoles 25 de septiembre (último día de actividades) inició a las 10:00 horas en el aula 2, donde se llevó a cabo el taller de elaboración de instrumentos prehispánicos. En este se terminaron las piezas de barro que los estudiantes habían comenzado el día anterior. En el desarrollo de las actividades los estudiantes pudieron interactuar con los instructores y ver la exposición presentada en uno de los pasillos de la facultad.

A las 12:00 horas en el auditorio Silvestre Revueltas se desarrolló la conferencia $E l$ arte sonoro en México, dictada por la doctora Mayela Villarreal. En esta actividad la expositora señaló que la composición en México había tenido una gran evolución a partir de la mitad del siglo XX hasta nuestros días, pues al incorporar los medios electrónicos se abrió un sinfín de posibilidades creativas en los planos sonoro y visual, lo cual ha dado como resultado diversas tipologías creativas que han sido concentradas en el llamado arte sonoro. En México han emergido importantes figuras que han destacado internacionalmente gracias al creciente número de festivales que han servido para difundir este arte híbrido que ofrece nuevas posibilidades creativas y de experiencia estética.

Luego, a las 16:00 horas en el aula magna de Colegio Civil se realizó el recital del coro del DIF bajo la dirección de la maestra Dora Elia Pérez González. Este coro se formó en marzo de 2013 por un programa de impacto social a través de la música dependiente de la Secretaría de Desarrollo Social de San Pedro. Está formado por los alumnos que pertenecen a las estancias de primaria y se han presentado en numerosos espacios de la ciudad. Cuentan con un vasto repertorio de música mexicana con el objetivo de promover el patrimonio cultural de nuestro país.

A las 18:00 horas en el aula magna se presentó la puesta en escena de El bolero, por el cantante Gerardo Rocha, egresado de la Facultad de Música. La propuesta fue una narración histórica mediante el uso de la canción mexicana, lo cual le significó un gran éxito debido a que fue una innovación dentro de este festival. Los autores de las canciones fueron Agustín Lara, Jorge del Moral, Alberto Domínguez, Consuelo Velázquez, María Grever, Tata Nacho, Alfonso Esparza Oteo, Armando Manzanero y tres canciones tradicionales de Oaxaca 


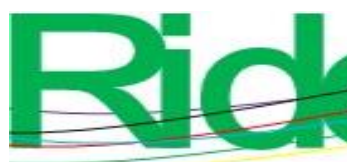

Revista Iberoamericana para la Investigación y el Desarrollo Educativo ISSN 2007 - 7467

y Veracruz.

Para finalizar este magno evento, a las 20:00 horas en el aula magna se presentó el ensamble Tierra Mestiza, el cual — además de contar con una amplia trayectoria a nivel internacional - tiene como objetivo difundir la música de concierto mexicana nutrida en las raíces del folclore y la música popular. Su repertorio abarca desde piezas del barroco mexicano hasta obras actuales. Los integrantes de este ensamble fueron los maestros Gerardo Tamez, Mercedes Gómez, Teodoro Gálvez y Carlos García. El auditorio estuvo pleno en este concierto en especial y el público se mostró gratamente satisfecho con las actividades que se ofrecieron en el IV Festival Internacional de Música Mexicana.

Por otra parte, y para conocer las percepciones de los asistentes, se empleó un cuestionario con preguntas de estimación, el cual "tiene la finalidad de clasificar las respuestas de acuerdo con su grado de intensidad, introducir el elemento de medida y en general evaluar opiniones o actitudes" (García-Córdoba, 2012, p. 76). La muestra estuvo conformada por 380 encuestados, los cuales habían asistido a por lo menos una de las actividades. Después de hacer el análisis y concluir la codificación se efectuaron las siguientes gráficas para representar visualmente los resultados.

Figura 1. Rango de edades de los participantes

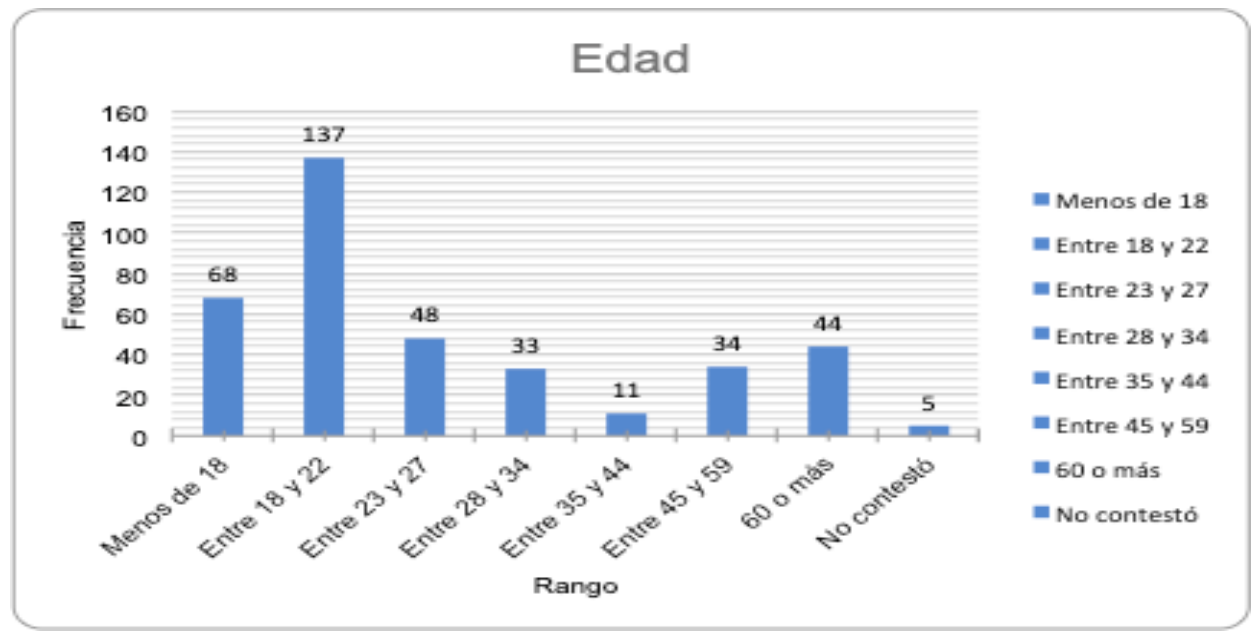

Fuente: Elaboración propia 


\section{Revista Iberoamericana para la Investigación y el Desarrollo Educativo ISSN $2007-7467$}

Figura 2. Nivel académico de los encuestados

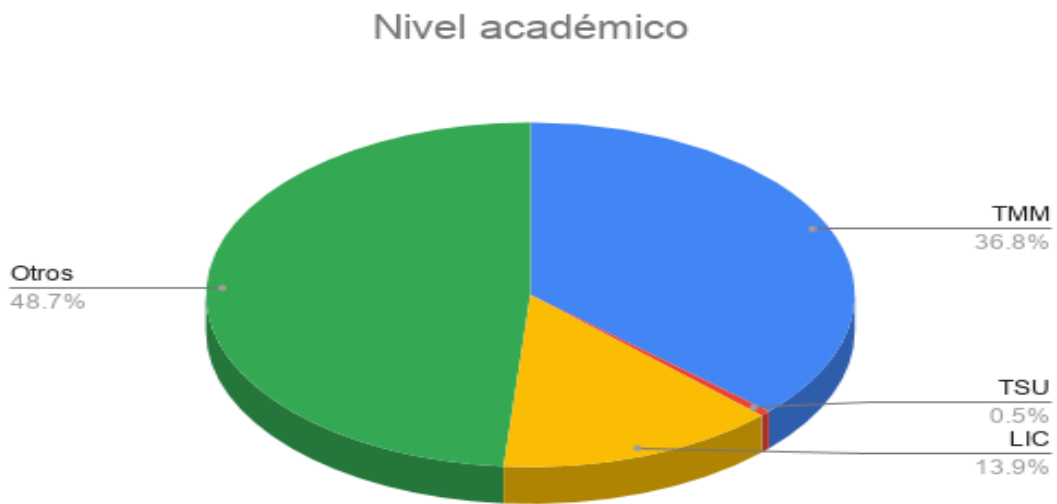

Fuente: Elaboración propia

Figura 3. Porcentaje de alumnos que contestaron el cuestionario

\section{Estudiante}

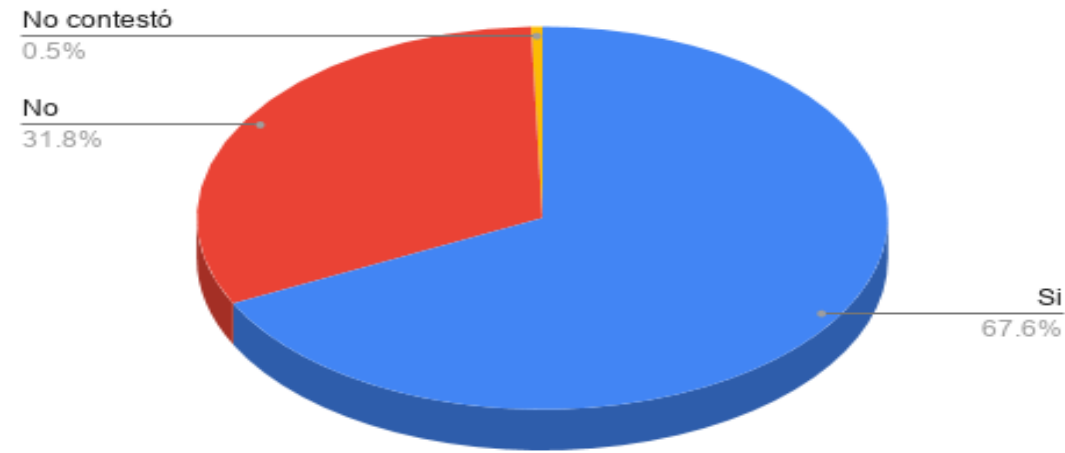

Fuente: Elaboración propia 


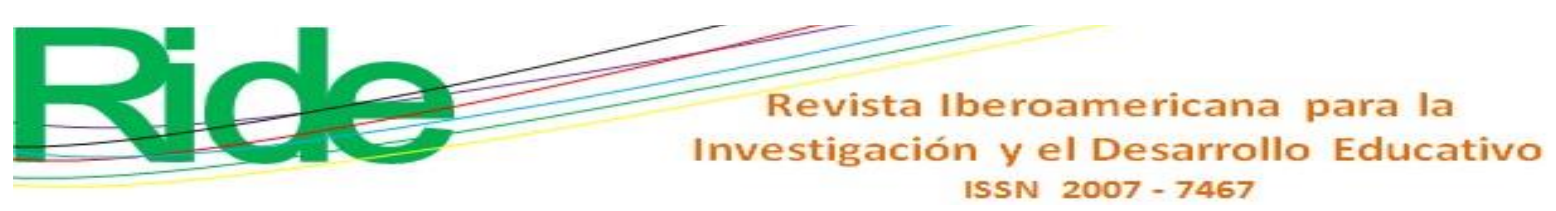

Figura 4. Primera pregunta del cuestionario

¿Conocía la existencia del Festival de Música

Mexicana?

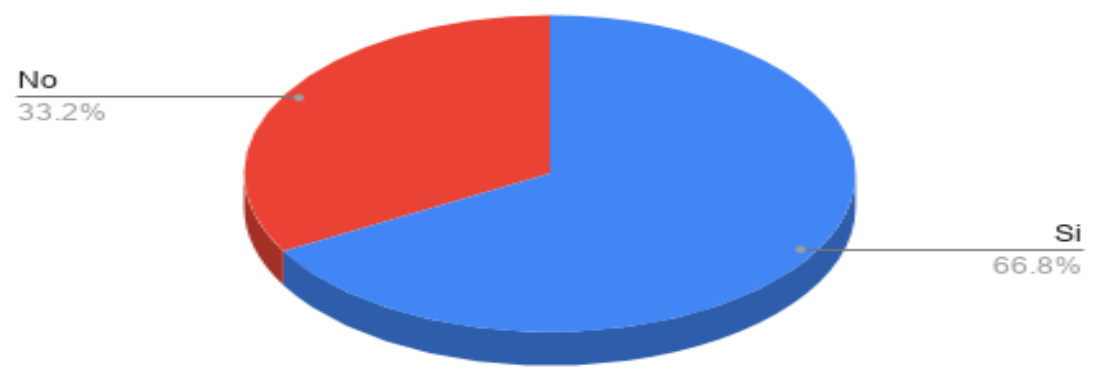

Fuente: Elaboración propia

Figura 5. Segunda pregunta del cuestionario

¿Conocía el contenido que se presentó en este evento?

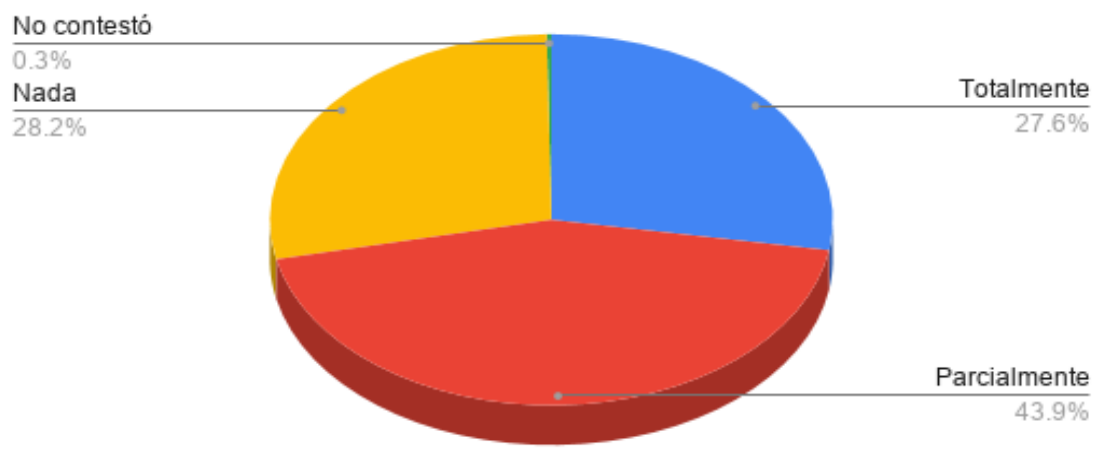

Fuente: Elaboración propia 


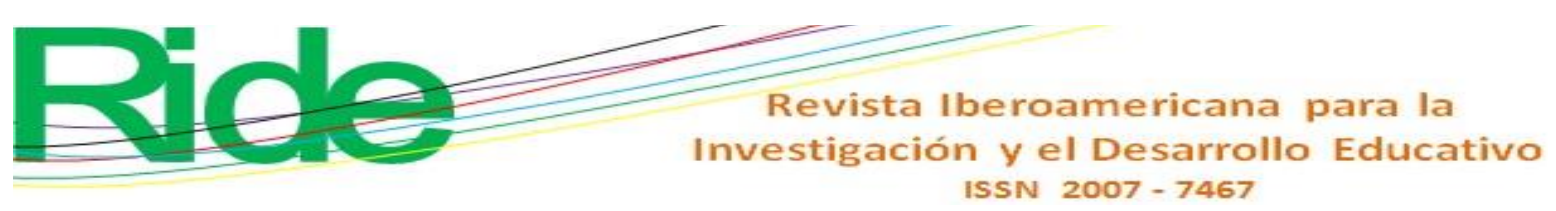

Figura 6. Tercera pregunta del cuestionario

¿Cómo se enteró del Festival de Música Mexicana?

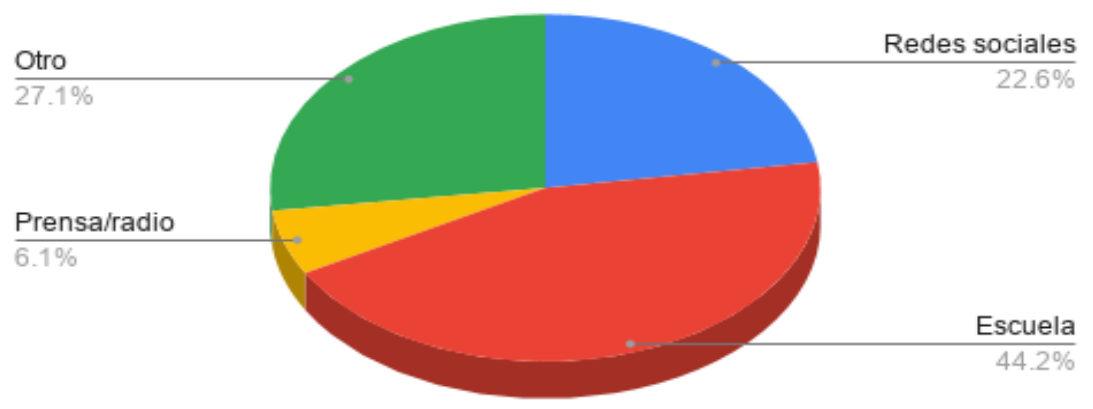

Fuente: Elaboración propia

Figura 7. Cuarta pregunta del cuestionario

¿Considera que el Festival Internacional de Música

Mexicana es enriquecedor y formativo?

De acuerdo

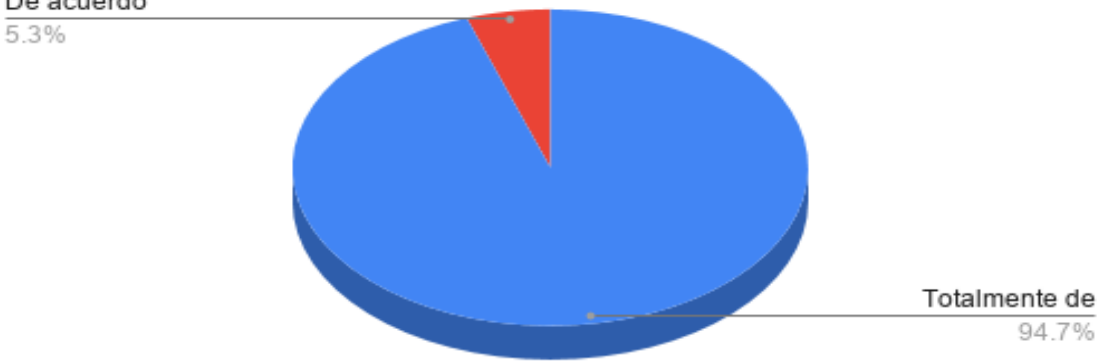

Fuente: Elaboración propia 


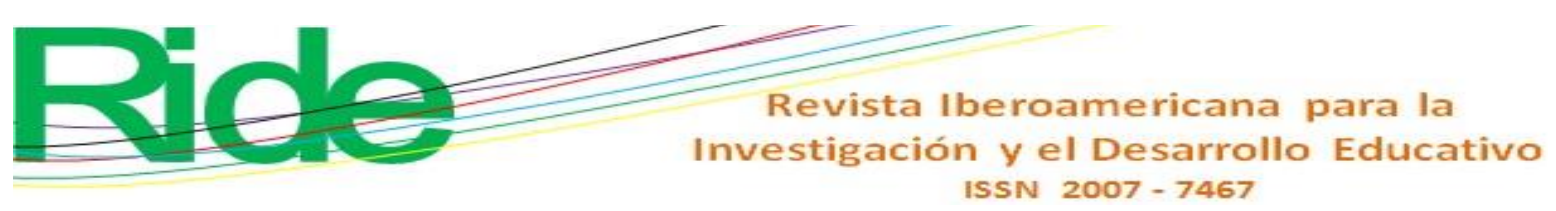

la Música en México, con talleres que sirven para conocer el uso y la elaboración de los instrumentos prehispánicos confeccionados artesanalmente, los cuales se siguen utilizando en algunas obras de concierto. También comentaron que esta actividad les sirve para enriquecer sus conocimientos musicales gracias a la participación de especialistas foráneos en las clases magistrales y en las conferencias. Por último, los participantes indicaron que esta propuesta enriquece el patrimonio musical de la ciudad, pues se tiene la oportunidad de asistir a las múltiples propuestas artísticas que ofrece el festival.

En síntesis, se puede afirmar que se logró el fortalecimiento académico de los estudiantes a través de esta estrategia educativa, lo que permitió crear nuevas áreas de oportunidad profesional para la comunidad artística que tiene el compromiso de rescatar, promover y difundir la música mexicana de concierto mediante esta plataforma cultural que ofrece al público en general un constante crecimiento y actualización del quehacer artístico de nuestro país. 


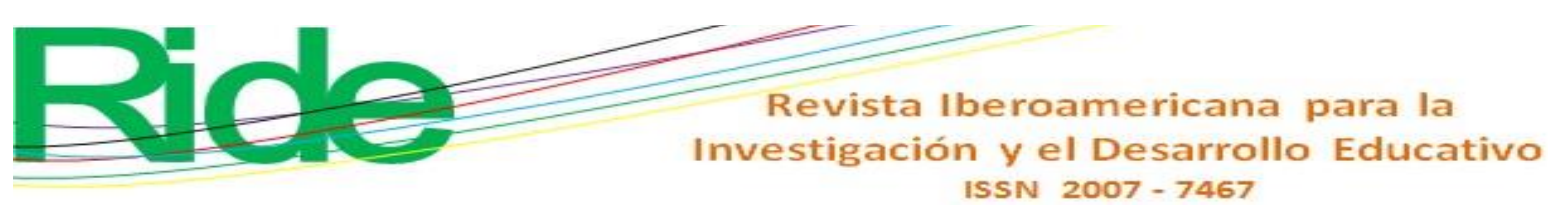

\section{Referencias}

Barrón, J. (2014). Escritos entorno a la música mexicana. México: Maporrua.

Chávez, C. (2018). Carlos Chávez y su mundo. México: El Colegio de Nacional.

Díaz, E. y Díaz, D. (2003). Ponce, genio de México. México: UJED.

García-Córdoba, F. (2012). El cuestionario. México: Limusa.

Gargallo, B., Almerich, G., Suárez-Rodríguez, J. y García Félix, E. (2012). Estrategias de aprendizaje en estudiantes universitarios excelentes y medios. Su evolución a la largo del primer año de carrera. Relieve, 18(2). Doi: 10.7203/relieve.18.2.2000

Gómez, L. (2006). La documentación de la iconografía musical prehispánica. Revista Digital Universitaria, 7(2).

González-Quintanilla, F. (1991). Los códices mexicanos y su contexto. Monterrey: Cuadernos del Archivo nro. 60.

Híjar, F. (2009). Cunas, ramas y encuentros sonoros, doce ensayos sobre el patrimonio musical de México. México: Fondo Nacional para la Cultura y las Artes

Latorre, A. (2013). La investigación-acción. Barcelona: Grao.

León, M. (2019). La música en la literatura náhuatl. México: El Colegio Nacional.

Marroquín, G. y Cavazos, P. (2012). La música prehispánica y su iconología. Monterrey, México: Universidad Autónoma de Nuevo León.

Ramírez de la Fuente, B. (2013). El arte prehispánico y la educación. México: El Colegio Nacional.

Sánchez, M., Carvajal, J., Lioba, M. y Castillo, G. (2016). Música e identidades: una lectura interdisciplinaria. México: Plaza y Valdés. 


\begin{tabular}{|l|l|}
\hline Rol de Contribución & Autor (es) \\
\hline Conceptualización & Beania Salcedo Moncada \\
\hline Metodología & Beania Salcedo Moncada \\
\hline Software & José María López \\
\hline Validación & José María López Prado \\
\hline Análisis Formal & Beania Salcedo Moncada \\
\hline Investigación & Beania Salcedo Moncada \\
\hline Recursos & José María López \\
\hline Curación de datos & Beania Salcedo Moncada 50\% y José María López 50\% \\
\hline $\begin{array}{l}\text { Escritura - Preparación del } \\
\text { borrador original }\end{array}$ & Beania Salcedo Moncada 70\% y José María López 30\% \\
\hline $\begin{array}{l}\text { Escritura - Revisión y } \\
\text { edición }\end{array}$ & . Beania Salcedo Moncada 60\% y José María López 40\% \\
\hline Visualización & Beania Salcedo Moncada \\
\hline Supervisión & José María López Prado \\
\hline Administración de Proyectos & Beania Salcedo Moncada López Prado \\
\hline Adquisición de fondos & José María \\
\hline
\end{tabular}

